\title{
Analyzing Burden of Cost of Therapy in Patients Affected with Acute Coronary Syndrome in Tertiary Care Hospital
}

\author{
Rao KN ${ }^{1 *}$, Reddy $\mathbf{G N}^{1}$, Vinny $\mathbf{N} 1$, Das $\mathrm{S}^{2}$, Dhanapal $\mathrm{CK}^{3}$ and Selvamuthukumaran $\mathrm{S}^{4}$ \\ ${ }^{1}$ Department of Pharmacy Practice, R.M Medical College\& Hospital, Annamalai University, India \\ ${ }^{2}$ Pharm-D, Department of Pharmacy Practice, Annamalai University, India \\ ${ }^{3}$ Associate Professor, Department of Pharmacy Practice, Annamalai University, India \\ ${ }^{4}$ Assistant Medical Superintendent, RMMCH, Annamalai University, Tamil Nadu, India
}

\begin{abstract}
Background: The present research deals with pharmacoepidemiology and pharmacoeconomic study of Acute Coronary Syndrome (ACS) and its impact on patient's therapeutic outcome and cost of therapy. According to a recent World Health Origination (WHO) report around 100 million people died every year due to poverty associated with illness. Contributing to the growing literature on the economic burden of illness, this article examines the indirect and direct costs of illness that occurs on household level, describes its influence on treatment seeking behavior and assesses its impact on household welfare.
\end{abstract}

Methods: The contemporary research was performed in Coronary Care Unit (CCU) and medicine ward department of medicine, RMMC and Hospital over 65 patients to illustrate the expenditure in harmony with achieved desired therapeutic outcomes by analyzing therapy cost of Acute Coronary Syndrome (ACS) supplemented via therapeutic outcomes using Minnesota Living with Heart Failure and Condition Questionnaire (MLHFCQ).

Results: The values were observed and recorded using appropriate data collection forms and MLHFC questionnaire. The total cost (TC) spent was recorded as 7,096.2 USD with most patients $(n=16 ; 35.61 \%)$ paying in cost range of (110.1 to 141.5 USD). The total direct therapy cost was $6,278.6$ USD accounting $88.47 \%$ of total cost and indirect cost 817.6 USD (11.52 \% of TC). Significant improvement observed in overall mean MLHFC score of 62.93 compared to the baseline score of 37.94 rated moderate.

Conclusion: The study was designed, planned and executed to estimate cost of the given therapy and direct effect on patient therapeutic outcome.

Keywords: Pharmacoepidemiology; Pharmacoeconomic; Therapeutic outcome; Acute coronary syndrome

Abbreviations: ACS: Acute Coronary Syndrome; WHO: World Health Origination; CVD: Cardio Vascular Disease; CHD: Coronary Heart Disease; CCU: Coronary Care Unit; DASH Diet: Dietary Approaches to Stop Hypertension Diet; MLHFCQ: Minnesota Living with Heart Failure \& Condition Questionnaire

\section{Introduction}

Acute Coronary Syndrome (ACS) is the leading cause of death in economically developed countries and is rapidly assuming serious dimensions in developing countries. It is expected to be the single most important cause of death in India by the year 2015 A.D [1]. According to the WHO, an estimated 17 million people died from Cardiovascular Disease (CVD) in 2005 comprising $30 \%$ of all global deaths and of these nearly $80 \%$ of deaths took place in low and middle income countries like India [2]. According to the World Heart Federation, 35\% of all CVD deaths in India occur in those aged 35-64 years [3]. Coronary Heart Disease (CHD) is the commonest CVD accounting for $90-95 \%$ of all cases and deaths.

Cost of therapy is defined as value of the resources that are expended or forgone as a result of a health problem. Cost of therapy is useful for both health care policy and burden of the disease (pharmacoepidemiological studies), is also useful for pharmacoeconomic studies to analyze the cost for a particular disease spent by a patient [4]. Cost of illness can be calculated in terms of direct cost (medical cost, admission cost etc.) and indirect cost (productivity cost like number of days lost and income lost during the time of therapy).
The research was conducted to analyze cost of therapy in both health care policy and burden of the disease (pharmacoepidemiological studies) and pharmacoeconomic study was done to analyze the cost for a particular disease spent by a patient and its impact in terms of patients' therapeutic outcomes [4].

\section{Methods}

\section{Study site}

The study was conducted in Coronary Care Unit (CCU) and Medicine Wards of Rajah Muttaih Medical College and Hospital (RMMCH), 1400 bedded Multi- Specialty Tertiary Care Teaching Hospital, Annamalai University.

\section{Sampling size}

The sampling size includes 65 patients in the study. *Corresponding author: Rao KN, Doctor of Pharmacy, Department of Pharmacy
Practice, R.M Medical College \& Hospital, Annamalai University, Tamil Nadu, India, Tel:+918122278271; E-mail: simha933@gmail.com

Received December 23, 2014; Accepted January 14, 2014; Published January 16,2015

Citation: Rao KN, Reddy GN, Vinny N, Das S, Dhanapal CK (2015) Analyzing Burden of Cost of Therapy in Patients Affected with Acute Coronary Syndrome in Tertiary Care Hospital. Adv Pharmacoepidemiol Drug Saf 3: 174. doi:10.4172/21671052.1000174

Copyright: ( 2015 Rao KN, et al. This is an open-access article distributed under the terms of the Creative Commons Attribution License, which permits unrestricted use, distribution, and reproduction in any medium, provided the original author and source are credited. 
Citation: Rao KN, Reddy GN, Vinny N, Das S, Dhanapal CK (2015) Analyzing Burden of Cost of Therapy in Patients Affected with Acute Coronary Syndrome in Tertiary Care Hospital. Adv Pharmacoepidemiol Drug Saf 3: 174. doi:10.4172/2167-1052.1000174

Page 2 of 3

\section{Subject recruitment procedure}

Patients who came to RMMCH affected with Acute Coronary Syndrome, admitted in inpatient medicine department and CCU of either gender during the period "December 2013 -May 2014", those who are not having any other co-morbidities and willing to co-operate were being recruited in our study. These patients were explained about the study and their consent was obtained along with signature and recorded (Tamil and English translations were provided).

\section{Selection criteria}

Inclusion criteria: Patients who were above 18 years of age, newly diagnosed with ACS, already being treated for ACS were included in the study. These patients were explained about the study and their consent was obtained along with signature and recorded (Tamil and English translations were provided).

Exclusion criteria: Patients with other co-morbidities with cardiovascular disorders, not willing to cooperate, vulnerable group (pregnant women, mentally retarded etc.) along with patients coming for general check-up (Out patients) were excluded from the study.

\section{Study design}

This study was a single blinded interventional research. This study was conducted over a group of 65 patients to evaluate the Pharmacoeconomic and pharmacoepidemiology of patients affected with acute coronary syndrome, therapeutic outcomes using Minnesota Living with Heart Failure \& Condition Questionnaire (MLHFCQ). Cost of therapy forms were designed with an objective to find economic burden of the ACS on each patient and is calculated in terms of direct cost (medical cost, admission cost etc.) and indirect cost (productivity cost like number of days lost and income lost during the time of therapy).

Patient were regularly followed once at the time of admission and while they were about to discharge. First Intervention includes collecting data to analyze cost of therapy and second Intervention was therapeutic outcomes using Minnesota Living with Heart Failure \& Condition Questionnaire (MLHFCQ), patient counselling about life style modification like low salt intake and dietary approaches to stop hypertension (DASH) diet. The interventions were designed by researchers along with the consultant physician.

Cost of therapy data collection forms were formulated which procured information regarding patients direct cost, indirect cost, total treatment cost, number of days spent in hospital and average cost per day. Other information like patient's lifestyle, socio-economic status also were recorded.

\section{Results}

\section{Patient demographic data}

A total number of 70 patients were enrolled in our study. Out of all the patients enrolled, 65 of them completed the study and remaining 5 were dropouts. The upcoming results were taken from the patients who successfully completed the study. The study population was consisting of 43 males $(66 \%)$ and 22 (34\%) females (Table 1). Majority of patients $(\mathrm{n}=27)$ i.e., $41.5 \%$ were belonging to $36-50$ age group. 19 patients $(29.3 \%)$ were belonging to the age group of $66-80,10$ patients(15.3\%) were between 51-65 age group, the age group was between 18-35 for 5 patients $(7.7 \%)$ and 4 were $>80$ years of age (Table 2 ).

\section{Cost of therapy}

The overall cumulative therapy cost for 65 patients was accounted as $7,096.2$ USD of which $35.61 \%$ of total cost was paid by 16 patients (110.1-141.5 USD), 33.22\% of total cost was spent by 24 patients (78.6110.1 USD), $17.92 \%$ was spent by 7 patients (>141.5 USD), $9.02 \%$ and $4.23 \%$ of total cost was spent by 10 and 8 patients respectively (47.278.6 and 15.7-47.2 USD) to improve their therapeutic outcome (Table 3). The average cost per illness spent by patient was 109.2 USD (Table 4) to improve his/her quality of life (nearly 28.06) from the time of admission (baseline score) to the time of discharge (outcome score).

\section{Therapeutic outcomes}

The therapeutic outcomes in patients with acute coronary syndrome were assessed by Minnesota Living with Heart Failure \& Condition Questionnaire (MLHFQ). At the time of admission, mean therapeutic outcomes of MLHFQ was 37.94\%. At the time of Discharge, overall mean therapeutic outcome of MLHFQ was $62.93 \%$. Significant improvement observed in overall mean therapeutic outcomes of MLHFQ observed (Table 5).

\section{Discussion}

As the prevalence of cardiovascular disorders is increasing worldwide, the study was targeted to assess the pharmacoeconomic

\begin{tabular}{|c|c|c|c|}
\hline S. No & $\begin{array}{c}\text { Gender Wise Distribution of } \\
\text { Patient }\end{array}$ & Male & Female \\
\hline 1. & No. of Patients & 43 & 22 \\
\hline 2. & Percentage & $66.2 \%$ & $33.8 \%$ \\
\hline
\end{tabular}

Table 1: Gender Wise Distribution of Patient

\begin{tabular}{|c|c|c|c|c|c|c|}
\hline S. No & $\begin{array}{c}\text { Age Group } \\
\text { (in Years) }\end{array}$ & $\mathbf{1 8 - 3 5}$ & $\mathbf{3 6 - 5 0}$ & $\mathbf{5 1 - 6 5}$ & $\mathbf{6 6 - 8 0}$ & $>\mathbf{8 0}$ \\
\hline 1. & No. of Patients & 5 & 27 & 10 & 19 & 4 \\
\hline 2. & Percentage & $7.7 \%$ & $41.5 \%$ & $15.3 \%$ & $29.3 \%$ & $6.2 \%$ \\
\hline \multicolumn{4}{|c|}{ Average } & \multicolumn{4}{|c|}{54.7 Years } \\
\hline
\end{tabular}

Table 2: Age Wise Distribution of Patients

\begin{tabular}{|c|c|c|c|c|c|c|}
\hline S. No & $\begin{array}{c}\text { Cost of } \\
\text { Therapy (in } \\
\text { USD) }\end{array}$ & $\mathbf{1 5 . 7 - 4 7 . 2}$ & $\mathbf{4 7 . 2 - 7 8 . 6}$ & $\mathbf{7 8 . 6 - 1 1 0 . 1}$ & $\mathbf{1 1 0 . 1 - 1 4 1 . 5}$ & $\mathbf{> 1 4 1 . 5}$ \\
\hline 1. & $\begin{array}{c}\text { No. Of } \\
\text { Patients }\end{array}$ & 8 & 10 & 24 & 16 & 7 \\
\hline 2. & $\begin{array}{c}\text { Percentage } \\
3 .\end{array}$ & $12.3 \%$ & $15.4 \%$ & $36.9 \%$ & $24.6 \%$ & $10.8 \%$ \\
\hline $\begin{array}{c}\text { Total Amount } \\
\text { (in USD) }\end{array}$ & 300.8 & 640.1 & $2,356.3$ & $2,527.5$ & $1,271.5$ \\
\hline $\begin{array}{c}\text { Average } \\
\text { Therapy Cost } \\
\text { (in USD) }\end{array}$ & & & 109.2 & \\
\hline
\end{tabular}

Table 3: Patient's Distribution Based on Therapy Cost

\begin{tabular}{|c|c|c|}
\hline Direct Cost (Cost in USD) & $\begin{array}{c}\text { Per patient/per day(cost } \\
\text { in USD) }\end{array}$ & Total cost (in USD) \\
\hline Bed charges & 1.6 & 11.0 \\
\hline Admission Charges & 4.7 & 4.7 \\
\hline Medical Charges & 5.3 & 36.8 \\
\hline Lab Data & - & 29.9 \\
\hline Travelling Expenses & 3.2 & 3.1 \\
\hline Miscellaneous & 1.6 & 11.0 \\
\hline Indirect Cost & - & 12.6 \\
\hline Total Cost(in USD) & - & 109.2 \\
\hline
\end{tabular}

Table 4: Cost of Therapy for average 7 days of Hospitalization 
Citation: Rao KN, Reddy GN, Vinny N, Das S, Dhanapal CK (2015) Analyzing Burden of Cost of Therapy in Patients Affected with Acute Coronary Syndrome in Tertiary Care Hospital. Adv Pharmacoepidemiol Drug Saf 3: 174. doi:10.4172/2167-1052.1000174

Page 3 of 3

\begin{tabular}{|c|c|c|c|c|c|}
\hline S. No & Scoring Range & $\mathbf{2 1 - 4 2}$ & $\mathbf{4 3 - 6 3}$ & $\mathbf{6 4 - 8 3}$ & $\mathbf{8 4 - 1 0 5}$ \\
\hline 1. & No of Patients & Poor & Moderate & Good & Very Good \\
\hline 2. & Admission & 23 & 42 & - & - \\
\hline 3. & Discharge & 2 & 18 & 29 & 16 \\
\hline
\end{tabular}

Table 5: Comparison of Therapeutic Outcomes at Beginning and Discharge

and pharmacoepidemiology status of cardiovascular disorders in accordance to the improvement of the disease condition and quality of life. The study showed that an acute episode of ACS occurred at age group of 36-50 yrs., which required hospitalization of about 7(6.39) days.

The total cost spent by total number of patients $(n=65)$ in the study was estimated/calculated to be 7,096.2 USD with most patients (24; $36.9 \%$ ) paying in cost range of (78.6 to 110.1 USD). On an average each patient spent 109.2 USD of which the total direct cost spent by these patients was 6,278.6 USD and total indirect cost was 817.6 USD. The average direct cost per patient for 7days was 96.6 USD and average indirect cost per patient for 7 days was 12.6 USD.

The number of patients that is 7 patients (10.8\%) paid therapy cost more than 141.5 USD and 8 patients $(12.3 \%)$ paid in between 15.7 to 47.2 USD as cost of therapy. The socioeconomic data showed that a significant number of patients (i.e., $38 ; 58.5 \%$ ) belonging to Below Poverty Line (BPL) with the monthly income of less than 15.7 USD and 27 patients (41.5\%) were above this poverty line [5]. Out of 38 patients below the poverty line all of them accepted that the health care cost they were paying was a major burden on them.

In the study conducted, the therapeutic outcomes regarding cardiovascular disorders were measured by the Minnesota Living with Heart Failure (condition) Questionnaire (MLHFCQ). MLHFCQ score was compared between baseline data obtained during the admission and final data during the discharge of patients. The therapeutic outcomes were monitored during the hospitalization days of patient by subsequent follow-ups. The baseline mean MLHFCQ score was found

to be 37.94 categorized as Poor score with $35 \%$ patients showing poor MLHFC score and 65\% patients showing moderate score.

\section{Conclusion}

The study was designed, planned and executed to estimate cost of the therapy and direct effect on patient quality of health. The study shows a good result and relation between paid cost and improved therapeutic outcome. The study demonstrated that treatment provided by the hospital was good but the affordability by the patient was a matter of concern as they mostly belong to Below Poverty Line (BPL). The results at the time of discharge are satisfactory and patient has more knowledge about disease state and the do's and don't in this physical state.

\section{Acknowledgement}

We express our profound \& sincere gratitude to our Institutional guides $\mathrm{Dr}$. C.K. Dhanapal, Associate professor, Department of Pharmacy and Hospital guide Dr. S Selvamuthukumaran, Reader, Department of Medicine, $\mathrm{RMMCH}$, Annamalai University, Annamalai Nagar for their valuable guidance and support, constant inspiration, kind co-operation and great intend to us to fulfil our work in a successfu manner.

We express our gratitude to Dr. P.K. Manna, professor, Department of Pharmacy for his constant encouragement, support and valuable suggestions throughout the duration of our project work

We thank all the patients who gave their consent and participated in the study, without whom the study would be nothing.

\section{References}

1. World Health Origination (2007) Prevention of cardiovascular disease: guidelines for assessment and management of total cardiovascular risk.

2. http://www.who.int/nmh/publications/fact_sheet_cardiovascular_en.pdf

3. Fuster V, Voute J (2005) MDGs: chronic diseases are not on the agenda. The Lancet 366:1512-14

4. Zhao Z, Winget M (2011) Economic burden of illness of acute coronary syndromes: medical and productivity costs. BMC Health Serv Res 11:35.

5. Reserve bank of India (2012) Number and percentage of population below poverty line. 